\title{
Response of a Copper(II) and Iron(III) Ion-Selective Electrode Bielectrode Array in Saline
}

\section{Media}

Roland De Marco ${ }^{1, *}$ and Jay Martizano ${ }^{1,2}$

${ }^{1}$ Nanochemistry Research Institute, Department of Applied Chemistry, Curtin University of Technology, GPO Box U1987, Perth, Western Australia, 6845, Australia

\begin{abstract}
A bielectrode array comprising a jalpaite membrane (i.e., $\mathrm{Ag}_{1.5} \mathrm{Cu}_{0.5} \mathrm{~S}$ ) copper(II) ionselective electrode (ISE) and chalcogenide glass membrane [i.e., $\mathrm{Fe}_{2.5}\left(\mathrm{Se}_{60} \mathrm{Ge}_{28} \mathrm{Sb}_{12}\right)_{97.5}$ iron(III) ISE has been assembled by individually wiring each solid-state sensor into a single electrode body. Furthermore, a dual metal ion buffer calibration standard incorporating copper(II) and iron(III) coordinating ligands to regulate the levels of free copper(II) and iron(III) in the buffer has been developed to enable simultaneous calibration of the bielectrode ISE array. In this work, the bielectrode ISE array has been employed in the continuous flow analysis (CFA) of free copper(II) and iron(III) in seawater media. It is shown that the individual electrodes displayed Nernstian response in the metal ion buffer calibration standard over a wide dynamic range (viz., $10^{-15}$ to $10^{-5}$ $\mathrm{MaCu}^{2+}$ and $10^{-21}$ to $10^{-11} \mathrm{M} \mathrm{aFe}^{3+}$ ), and the results of repetitive CFA analyses of free copper(II) and iron(III) in seawater are commensurate with the typical values found in coastal seawater samples. Clearly, the bielectrode ISE array may be used in the simultaneous analysis of free copper(II) and iron(III) in seawater without fear of cross interference between the solid-state sensors.
\end{abstract}

Keywords: ion-selective electrode; trace metals; metal speciation; copper and iron; seawater

* Corresponding author: Tel: +61 89266 7322; Fax: +61 89266 2602; E-mail: r.demarco@curtin.edu.au

${ }^{2}$ Present address: University of the Philippines in the Visayas, Miag-ao, Iloilo, Philippines, 5023 


\section{Introduction}

Despite the possibility of using ion-selective electrodes (ISEs) in the analysis of environmentally important trace metals such as copper(II) and iron(III), a past misconception has been that ISE devices lack the sensitivity and selectivity needed for the analysis of trace analytes in complex and challenging samples such as seawater.

Notwithstanding, there were several excellent papers in the 1970's and 1980's [1-4] demonstrating that it is possible to use a crystalline membrane copper ISE in the analysis of nanomolar levels of copper in natural waters, as long as the ISE is handled correctly, so as to minimize the dissolution of the ISE and the concomitant carry-over of copper from sample to sample. Clearly, these seminal papers laid the foundations for the use of solid-state membrane ISEs in environmental analysis.

The great virtue of ISEs in environmental analysis is their ability to sense the free metal ion activity, which is widely recognized as a master variable governing the uptake and toxicity of metals by biota [5], thereby providing an analytical technique capable of monitoring the impact of trace metal inputs in the environment. Notably, the free metal content of environmental waters is regulated by the metal buffering ability of the natural water [5], as dictated by the inorganic and organic speciation of metals in the sample, and this is a critical factor in determining the fates of trace metals in the marine environment.

Copper is a major trace metal in the environment due to its extensive use in antifouling paints, and poses a serious environmental threat at high levels due to its toxicity [6]. Essentially, copper is an essential trace metal nutrient at ambient levels $[7,8]$, and it has been demonstrated on a variety of aquatic organisms [7-11] that the toxicity of copper on marine biota is related to free copper(II) or $\mathrm{Cu}^{2+}$, not the concentration of total dissolved copper. This is the single most 
important feature that makes the copper ISE so attractive in environmental science leading to considerable research in the development of copper ISE methods for the analysis of natural samples (i.e., seawater, lakes, rivers, soils, etc.) [1-4, 6-9, 12-24].

Iron is an important limiting trace metal nutrient in marine waters [25-27], as it limits the growth of phytoplankton and biomass production in the ocean. Since iron finds its way into marine environments by atmospheric dust deposition and by upwelling of water, it is present at very low levels in isolated areas such as Antarctica, and this was demonstrated clearly in an iron fertilization event in The Southern Ocean that led to a phytoplankton bloom in the fertilization zone [28, 29].

A seminal paper by Zirino et al. [13] has demonstrated the positive influence of hydrodynamic flow [either at a rotating disc electrode or in a continuous flow analysis (CFA) flowcell] in lowering the detection limit of the jalpaite membrane copper(II) ISE [13] to nanomolar levels, and this led to the conclusion that ISE determinations of trace metals in seawater are undertaken ideally in a flow-injection analysis (FIA) or CFA analysis mode. Accordingly, Eriksen et al. [20] developed a CFA method for the analysis of free and total copper in Pacific Ocean seawater, and found that the total copper levels obtained by ISE potentiometry in acidified seawater compared favourably with those determined using graphite furnace atomic absorption spectrometry (GFAAS). Furthermore, De Marco et al. [30] developed a chalcogenide glass membrane iron(III) ISE CFA method for the determination of free iron(III) in acidified and UV photooxidized Southern Ocean or open ocean seawater, and found that the CFA ISE method yielded a $\log \left(\mathrm{aFe}^{3+}\right)$ value for 10 repetitive injections of seawater that correlated brilliantly with the expected iron(III) speciation calculated using a inorganic speciation model for seawater. Clearly, the results of these previous studies have demonstrated the power of CFA in the ISE analysis of free copper(II) and iron(III) in seawater. 
The present study integrates the aforesaid copper(II) and iron(III) ISE-CFA analysis techniques into a single "all solid-state" bielectrode array method including conventional copper(II) and iron(III) ISEs, so as to enable the simultaneous analysis of free copper(II) and iron(III) in seawater. This technique is likely to appeal to environmental analytical scientists since copper(II) is a potent environmental threat due to its extensive use in antifouling paints [6], while iron(III) is a limiting nutrient that regulates the growth of phytoplankton and biomass production in the ocean [25-27]. This represents a significant improvement in methodology since it will enable simultaneous and rapid determinations of these environmentally important analytes in marine waters within approximately a minute, as opposed to lengthy analyses of $>10$ minutes duration while each analyte is assayed separately using single electrodes [i.e., > 20 minutes for copper(II) and iron(III) or $\mathrm{n}$ analytes $\mathrm{X}>20$ minutes], especially if a tested and proven extrapolation method is used to estimate the steady-state CFA signals of the ISEs using the first minute or so of simultaneously recorded potential time transients in a sample $[20,30]$. In this context, we have used the previously published electrode array approach of Shatkin, Szejnwald-Brown and Licht [31] in the fabrication of a bielectrode ISE array [see Figure 1 for a schematic diagram of the copper(II) and iron(III) bielectrode array]. Clearly, this study has necessitated the development of a combined copper(II) and iron(III) calibration buffer, and a study of the CFA potentiometric response characteristics of the bielectrode array in the calibration buffer was deemed necessary to ascertain if there are any cross-interference and cross-contamination effects from one electrode to the other in a combined metal ion buffer solution. Last, a CFA analysis of raw seawater was undertaken to ascertain the suitability of the new bielectrode array for the simultaneous determination of free copper(II) and iron(III) in seawater. 


\section{Experimental}

\section{Copper(II) and Iron(III) ISE Membranes}

The $\mathrm{Cu}(\mathrm{II})$ ISE membrane was prepared according to the procedure described elsewhere by Heijne, van Der Linden and Boef [32]. This procedure involves the slow addition of a solution consisting of 0.02 mole of $\mathrm{Cu}\left(\mathrm{NO}_{3}\right)_{2}$ and 0.04 mole $\mathrm{AgNO}_{3}(50 \mathrm{~mL})$ drop wise to $1 \mathrm{M} \mathrm{Na}_{2} \mathrm{~S}(72$ $\mathrm{mL})$ to produce jalpaite $\left(\mathrm{Cu}_{0.5} \mathrm{Ag}_{1.5} \mathrm{~S}\right)$ powder. The above-mentioned solutions were cooled to $2{ }^{\circ} \mathrm{C}$ before addition, and the resultant precipitate and supernatant were gradually heated to $70-75{ }^{\circ} \mathrm{C}$ for 40 minutes and maintained at that temperature for an additional 30 minutes. The precipitate was washed four times with deionized water $(200 \mathrm{~mL})$ at $70{ }^{\circ} \mathrm{C}$ followed by one time in $0.1 \mathrm{M}$ nitric acid $(100 \mathrm{~mL})$ at $70{ }^{\circ} \mathrm{C}$. The precipitate was rinsed with Milli-Q water at room temperature to remove any acid from the precipitate, and the filtered powder was rinsed with acetone prior to drying at $80{ }^{\circ} \mathrm{C}$. A pressed disk was prepared from the jalpaite powder by applying a pressure of $7600 \mathrm{~kg} \mathrm{~cm}^{-2}$, and it was fashioned into a small disk that is suitable for use in the bielectrode ISE array using emery paper.

The chalcogenide glass membrane Fe(III) ISE with a composition $\mathrm{Fe}_{2.5}\left(\mathrm{Se}_{60} \mathrm{Ge}_{28} \mathrm{Sb}_{12}\right)_{97.5}$ [33] was prepared by mixing appropriate amounts of the pure metallic powders [viz., iron (96\% purity, Ajax Chemical Co.), selenium (99.5\% purity, Aldrich), germanium (99.99\% purity, Aldrich) and antimony (99.999\% purity, Aldrich)] in a Vycor ampoule $(6 \mathrm{~cm}$ long, $13 \mathrm{~cm}$ diameter, $1 \mathrm{~mm}$ thickness). A total weight of $3 \mathrm{~g}$ was used, and the evacuated ampoule was sealed prior to heating. The ampoule was heated for 24 hours at $1030{ }^{\circ} \mathrm{C}$ followed by cooling to room temperature in air [33]. The resultant glass was annealed at $240{ }^{\circ} \mathrm{C}$ for 2 hours to remove any stress in the glass [33]. The glass was shaped into a small disk for use in the bielectrode ISE array. 


\section{Assembly of the Bielectrode ISE}

The bielectrode ISE was assembled by incorporating both the jalpaite membrane copper(II) ISE and chalcogenide glass membrane ISE into a single electrode body (see Figure 1). The individual membranes were attached to separate copper wires using silver epoxy contacts, noting that the electrode configuration could accommodate several additional electrodes [mercury(II) and cadmium(II) ISEs] if desired, thereby making this electrode array a potentially powerful research tool in environmental science. The contacts were allowed to dry for 24 hours at room temperature prior to sealing both electrodes into a cylindrical Perspex electrode housing by using epoxy cement taking great care to ensure that the ISEs were isolated electrically. Note, the epoxy resin was allowed to cure for 48 hours, and the bielectrode tip was polished on 500 grit silicon carbide paper to expose the membrane surface of the electrode followed by mechanical polishing sequentially on 1000 grit silicon carbide paper and on Stuers ${ }^{\mathrm{TM}} 1$ micron diamond spray in conjunction with Stuers $^{\mathrm{TM}}$ red lubricant and a Stuers ${ }^{\mathrm{TM}}$ polishing cloth until a mirror finish was obtained.

\section{Ethylenediamine-Salicylate-EDTA Dual Buffer for Copper(II) and Iron(III)}

A combined copper-iron buffer was prepared using $10^{-4} \mathrm{M} \mathrm{FeCl}_{3}, 10^{-3} \mathrm{M} \mathrm{Cu}\left(\mathrm{NO}_{3}\right)_{2}, 10^{-2} \mathrm{M}$ sodium salicylate, $1.50 \times 10^{-2} \mathrm{M}$ ethylenediamine (en), $10^{-4} \mathrm{M}$ EDTA and $0.600 \mathrm{M} \mathrm{NaNO}_{3}$ in MilliQ high-purity water (>18 M $\Omega$ resistivity). The $\mathrm{pH}$ was adjusted between $\mathrm{pH} 5-9.5$ to give a pFe range of 11 to 21 and $\mathrm{pCu}$ range of 5 to 15 (encompassing the typical $\mathrm{pCu}$ and $\mathrm{pFe}$ values of seawater) using analytical grade reagent sodium hydroxide and/or hydrochloric acid and the solutions were equilibrated at each $\mathrm{pH}$ for at least 30 minutes, with the free copper(II) and iron(III) levels at the equilibrium $\mathrm{pH}$ values calculated using the MINTEQA2 V3.11 software obtained from the Scientific Software Group (USA). 


\section{CFA Analysis with the Bielectrode ISE}

In CFA with the bielectrode ISE, a flow cell obtained from Chem Flow Devices (Melbourne Australia) was utilized (see Figure $2[30,34])$. This flow cell has a wall jet design that could take a standard size, flat-ended ISE. The reference electrode, which was prepared by anodizing silver wire in chloride media, was built into the device. An Autoclude ${ }^{\mathrm{TM}}$ Model VIL peristaltic pump was used to transport two streams of solution into the flow cell at a flow-rate of $5 \mathrm{ml}$ per minute. The calibration buffer solution and the sample stream passed directly below the ISE, while that of the reference solution $(0.60 \mathrm{M} \mathrm{KCl})$ went through the side of the device where it came into contact with the $\mathrm{Ag} / \mathrm{AgCl}$ reference electrode. The two solution streams merged into one before leaving the device as waste. All connections in the CFA manifold were made using Tygon ${ }^{\mathrm{TM}}$ tubing $(0.0449$ inch I.D., 0.1124 inch O.D.) with the fitting of 3-stop silicon tubing (2.54 mm I.D.) to the peristaltic pump. The CFA manifold $[30,34]$ is presented in Figure 3.

A freshly polished and newly calibrated ISE was employed in all cases. Solutions were stored in polyethylene containers that had been soaked in $10 \mathrm{wt} . \%$ nitric acid for 2 days prior to rinsing with copious amounts of Milli-Q high-purity water (>18 $\mathrm{M} \Omega$ resistivity). The electrode was equilibrated with a sacrificial $\mathrm{pCu} \approx 15$ and $\mathrm{pFe} \approx 22$ prior to the analysis of each seawater sample, thereby minimizing the electrode carry-over of adsorbed $\mathrm{Cu}^{2+}$ and $\mathrm{Fe}^{3+}$. A seawater sample (several hundred millilitres) was collected from The Aquaculture laboratory at the Muresk Institute of Agriculture at Curtin University, and the unfiltered and unadulterated sample (at $\mathrm{pH} 8$ ) was used in the ISE analysis of free copper(II) and iron(III) in seawater using CFA. 


\section{Results and Discussion}

\section{Copper(II) and Iron(III) Speciation in the Calibration Buffer}

Recent work by De Marco and co-workers [35] used electrochemical impedance spectroscopy (EIS)/synchrotron radiation-grazing incidence X-ray diffraction (SR-GIXRD) to monitor in-situ the surface chemistry of the iron(III) ISE in artificial and real seawater showing that the surface crystalline phases of this sensor (i.e., metal selenides) are attacked aggressively by chloride and hydroxide in organic-free or artificial seawater, but this deleterious process is suppressed significantly by the natural organic ligands in seawater. The EIS/SR-GIXRD data revealed a destruction of the surface layer of the ISE in organic-free or artificial seawater due to a complete removal of all surface crystalline phases, while raw seawater comprising natural organic ligands and a seawater ligand mimetic system containing en, salicylate, EDTA along with millimolar and sub-millimolar amounts of iron and copper is capable of protecting the iron(III) ISE's surface against this destructive dissolution process. In later research by the authors [34], it was demonstrated that this seawater ligand mimetic was capable of averting the seawater ligand interference on the chalcogenide glass membrane iron(III) ISE allowing reliable determinations of free iron(III) in seawater, and this is the reason for its selection as the calibration buffer in the present study.

Table 1 lists the equilibria and major species that are implicated in the MINTEQA2 V3.11 calculations of the metal speciation in the calibration buffer system. The MINTEQA2 V3.11 software uses its database of equilibrium constants, $K$, at zero ionic strength, $I$, and utilizes a socalled ion association model to correct to $K(I)$ taking account of the variation in activity coefficients, $\gamma$, as a function of I, viz.

$\log K(I)=\log K+\sum v \log \gamma$ 
and

$$
\log \gamma=-0.511 Z^{2} \sqrt{I} /(1+B \sqrt{I})+C I+D I^{3 / 2}
$$

where $\sum v \log \lambda$ represents the sum of multiples of $v \log \gamma$ for reactants minus the sum of $v \log \gamma$ for products, $v$ denotes the reaction stoichiometric coefficients, $Z$ is the charge carried by each individual ion, and $B, C$ and $D$ are constants for each individual ion. Ultimately, the inherent algorithm in MINTEQA2 V3.11 establishes and solves the appropriate mass and charge balances associated with equilibration of all of the species presented in Table 1.

The free copper(II) and iron(III) levels at the equilibrium $\mathrm{pH}$ values in the calibration buffer were calculated using the MINTEQA2 V3.11 software obtained from the Scientific Software Group (USA). In this medium, it is evident that an adjustment of the $\mathrm{pH}$ leads to deprotonation/protonation of the copper(II) and iron(III) binding ligands (i.e., ethylene diamine, salicylic acid and EDTA) in the buffer solution influencing the speciation of copper(II) and iron(III) in the buffer, and this behaviour is exemplified by the MINTEQA2 V3.11 speciation data for the calibration buffer that are presented in Figure 4.

An examination of Figure 4 shows that the $\mathrm{pCu}$ and $\mathrm{pFe}$ values in the buffer in the $\mathrm{pH}$ range of 5 to 9 are $\mathrm{pFe}=10-21$ and $\mathrm{pCu}=5-15$, respectively. Given that free and total levels of copper(II) and iron(III) in seawater generally fall within the ranges, $\mathrm{pCu}_{\text {total }}=8-10$ and $\mathrm{pCu}_{\text {free }}=$ $11-13[7-11,23]$ as well as $\mathrm{pFe}_{\text {total }}=9.0-10.7$ and $\mathrm{pFe}_{\text {free }}=19.5-21.2[25-27,36,37]$, a pH range of 5 to 9 is ideally suited to providing a calibration range applicable to the analysis of free copper(II) and iron(III) in raw seawater, as well as total copper(II) and iron(III) in acidified seawater that breaks down all of the copper(II) and iron(III) complexes in seawater yielding the level of total dissolved metal [12, 20]. 


\section{CFA Response of the Bielectrode ISE in the Calibration Buffer}

Figure 5 presents the CFA response curves for the bielectrode ISE array over the pCu range of 5 to 15 and pFe range of 10 to 21 , and it is clearly evident that the monotonic response of the copper(II) ISE in the bielectrode array reaches a steady-state value within seconds of a stepwise change in the activity of $\mathrm{Cu}^{2+}$ in the different buffers, while the iron(III) ISE response is slightly slower needing about 10-100 seconds to achieve a steady-state potential. Notwithstanding, a 10100 second response time, especially considering that the bielectrode ISE is simultaneously detecting both copper(II) and iron(III) in the sample, is excellent and permits an entire calibration of the bielectrode ISE within minutes.

Figures 6(a) and 6(b) present the CFA potentiometric response curves for the copper(II) and iron(III) ISEs of the bielectrode in the combined calibration buffer. It is evident that both ISEs in the bielectrode yielded the theoretical Nernstian response obtainable with these sensors, i.e., about $29 \mathrm{mV}$ per decade change in the activity of $\mathrm{M}^{\mathrm{n}+}$. Obviously, the combined calibration buffer is not inducing any electrode errors on the copper(II) and iron(III) ISEs, and there is no evidence of any cross interference or cross contamination between the copper(II) and iron(III) ISEs in the bielectrode array.

\section{CFA Analysis of Seawater}

It is important to note that quadruplicate CFA measurements of free $\mathrm{Cu}(\mathrm{II})$ and $\mathrm{Fe}(\mathrm{III})$ concentrations in seawater using the bielectrode ISE and the combined buffer yielded values of $\mathrm{pCu}=12.16 \pm 0.21$ and $\mathrm{pFe}=20.2 \pm 0.32$, noting that the copper(II) and iron(III) ISE techniques have been validated previously $[12,20,23,30,38]$ and that the present values compare favourably with recent data obtained by Millero, Yao and Aicher [27] as well as Eriksen et al. [20, 23] for free copper(II) and iron(III) in seawater, respectively. It is worth noting that the CFA response curves of 
the copper(II) ISE in seawater (not shown) required about ten minutes to achieve a steady-state value, and this is consistent with previous reports by Eriksen et al. [20]. Nevertheless, Eriksen et al. [20] demonstrated that it is possible to employ an electrode kinetic model describing the response characteristics of the ISE to extrapolate reliably the steady-state potential of the copper(II) ISE using the first couple of minutes of the potential time transient following a switch to seawater, and De Marco, Pejcic and Wang [30] showed that this extrapolation method is also applicable to the iron(III) ISE. Clearly, simultaneous measurements of analyte concentrations using the bielectrode ISE array in conjunction with an extrapolation method to predict the steady-state potentials of the individual ISEs following a switch into a seawater sample will provide a powerful method for the rapid and reliable analysis of copper(II) and iron(III) in seawater.

\section{Conclusions}

The results of this study demonstrate that a copper(II) and iron(III) bielectrode ISE array and a combined copper(II) and iron(III) calibration buffer can be used in the rapid and reliable calibration of a CFA system within minutes. Accordingly, it is possible to employ the calibrated bielectrode ISE array in the CFA electroanalysis of free copper(II) and iron(III) in raw seawater.

The sluggish response of the copper(II) ISE in seawater (with over 10 minute equilibration times) may be averted by using an extrapolation method to predict reliably the steady-state potential using the initial data (first minute or so) in the potential time transient of a seawater sample, and this provides scope for sample throughputs of 30-60 samples per hour.

\section{Acknowledgments}

The Australian Research Council (ARC) and Australian Institute of Nuclear Science and Engineering (AINSE) are acknowledged for financial support. 


\section{References}

[1] A. Zirino, P.F. Seligman, Mar. Chem., 10 (1981) 249.

[2] M.J. Smith, S.E. Manahan, Anal. Chem., 45 (1973) 836.

[3] R. Jasinski, I. Trachtenberg, D. Andrychuk, Anal. Chem., 46 (1974) 364.

[4] A. Zirino, C. Clavell, P.F. Seligman, Mar. Chem., 12 (1983) 25.

[5] J. Buffle, R.S. Altman, M. Filella, A. Tessier, Geochim. Cosmochim. Acta, 54 (1990) 1535.

[6] S.L. Belli, A. Zirino, Anal. Chem., 65 (1993) 2583.

[7] W.G. Sunda, P.A. Gillespie, J. Mar. Res., 37 (1979) 761.

[8] W. Sunda, R.L. Guillard, J. Mar. Res., 34 (1976) 511.

[9] W.G. Sunda, A.M. Lewis, Limnol. Oceanogr., 23 (1978) 870.

[10] K.H. Coale, K.W. Bruland, Limnol. Oceanogr., 33 (1988) 1084.

[11] K.W. Bruland, E.L. Rue, J.R. Donat, S.A. Skrabal, J.W. Moffett, Anal. Chim. Acta, 405 (2000) 99 .

[12] R. De Marco, D.J. Mackey, A. Zirino, Electroanalysis, 9 (1997) 330.

[13] A. Zirino, R. De Marco, I. Rivera, B. Pejcic, Electroanalysis, 14 (2002) 493.

[14] M. Camusso, G. Tartari, A. Zirino, Environ. Sci. Technol., 25 (1991) 678.

[15] R. De Marco, Anal. Chem., 66 (1994) 3202.

[16] M.T. Neshkova, Anal. Chim. Acta, 273 (1993) 255.

[17] A. Zirino, S.L. Belli, D.A. van der Weele, Electroanalysis, 10 (1998) 423.

[18] A. Zirino, D.A. VanderWeele, S.L. Belli, R. De Marco, D.J. Mackey, Mar. Chem., 61 (1998) 173.

[19] R. Stella, M.T. Ganzerli-Valentini, Anal. Chem., 51 (1979) 2148.

[20] R.S. Eriksen, D.J. Mackey, P. Alexander, R. De Marco, X.D. Wang, J. Environ. Monit., 1 (1999) 483. 
[21] I. Rivera-Duarte, A. Zirino, Environ. Sci. Technol., 38 (2004) 3139.

[22] I. Rivera-Duarte, G. Rosen, D. Lapota, D.B. Chadwick, L. Kear-Padilla, A. Zirino, Environ. Sci. Technol., 39 (2005) 1542.

[23] R.S. Eriksen, D.J. Mackey, R. van Dam, B. Nowak, Mar. Chem., 74 (2001) 99.

[24] D.J. Mackey, A. Zirino, Anal. Chim. Acta, 284 (1994) 635.

[25] M. Gledhill, C.M.G. van den Berg, Mar. Chem., 47 (1994) 41.

[26] E.L. Rue, K.W. Bruland, Mar. Chem., 50 (1995) 117.

[27] F.J. Millero, W. Yao, J. Aicher, Mar. Chem., 50 (1995) 21.

[28] E.R. Abraham, C.S. Law, P.W. Boyd, S.J. Lavender, M.T. Maldonado, A.R. Bowie, Nature, 407 (2000) 727.

[29] A.J. Watson, D.C.E. Bakker, A.J. Ridgwell, P.W. Boyd, C.S. Law, Nature, 407 (2000) 730.

[30] R. De Marco, B. Pejcic, X.D. Wang, Lab. Robot. Autom., 11 (1999) 284.

[31] J.A. Shatkin, H.S. Brown, S. Licht, Anal. Chem., 67 (1995) 1147.

[32] G.J.M. Heijne, W.E. van Der Linden, D.G. Boef, Anal. Chim. Acta, 89 (1977) 287.

[33] C.E. Koenig, E.W. Grabner, Electroanalysis, 7 (1995).

[34] R. De Marco, J. Martizano, Electroanalysis, 19 (2007) 2513.

[35] R. De Marco, Z.-T. Jiang, J. Martizano, A. Lowe, B. Pejcic, A. van Riessen, Electrochim. Acta., 51 (2006) 5920.

[36] M. Gledhill, C.M.G. van den Berg, Mar. Chem., 50 (1995) 51.

[37] J. Wu, G.W. Luther III, Mar. Chem., 50 (1995) 159.

[38] R. De Marco, D.J. Mackey, Mar. Chem., 68 (2000) 283. 
Table 1 MINTEQA2 V3.11 equilibria used to solve for $\mathrm{pCu}$ and $\mathrm{pFe}$ in the calibration buffer used in this study.

\begin{tabular}{|c|c|}
\hline Species & Solution Reaction \\
\hline$[\mathrm{Cu}(\mathrm{en})]^{2+}$ & $\mathrm{Cu}^{2+}+\mathrm{en} \Leftrightarrow[\mathrm{Cu}(\mathrm{en})]^{2+}$ \\
\hline$\left[\mathrm{Cu}(\mathrm{en})_{2}\right]^{2+}$ & $\mathrm{Cu}^{2+}+2 \mathrm{en} \Leftrightarrow\left[\mathrm{Cu}(\mathrm{en})_{2}\right]^{2+}$ \\
\hline$[\mathrm{Fe}(\text { salicylate })]^{+}$ & $\mathrm{Fe}^{3+}+$ salicylate $^{2-} \Leftrightarrow[\mathrm{Fe}(\text { salicylate })]^{+}$ \\
\hline$\left[\mathrm{Fe}(\text { salicylate })_{2}\right]^{-}$ & $\mathrm{Fe}^{3+}+2$ salicylate $^{2-} \Leftrightarrow\left[\mathrm{Fe}(\text { salicylate })_{2}\right]^{-}$ \\
\hline$[\mathrm{Fe}(\mathrm{EDTA})]^{-}$ & $\mathrm{Fe}^{3+}+\mathrm{EDTA}^{4-} \Leftrightarrow[\mathrm{FeEDTA}]^{-}$ \\
\hline $\mathrm{Fe}(\mathrm{HEDTA})$ & $\mathrm{Fe}^{3+}+\mathrm{HEDTA}^{3-} \Leftrightarrow \mathrm{Fe}($ HEDTA $)$ \\
\hline$[\mathrm{Fe}(\mathrm{OH}) \mathrm{EDTA}]^{2-}$ & $\mathrm{Fe}^{3+}+\mathrm{H}_{2} \mathrm{O}+\mathrm{EDTA}^{4-} \Leftrightarrow[\mathrm{Fe}(\mathrm{OH}) \mathrm{EDTA}]^{2-}+\mathrm{H}^{+}$ \\
\hline$\left[\mathrm{Fe}(\mathrm{OH})_{2} \mathrm{EDTA}\right]^{3-}$ & $\mathrm{Fe}^{3+}+2 \mathrm{H}_{2} \mathrm{O}+\mathrm{EDTA}^{4-} \Leftrightarrow\left[\mathrm{Fe}(\mathrm{OH})_{2} \mathrm{EDTA}^{3-}+2 \mathrm{H}^{+}\right.$ \\
\hline$[\mathrm{Fe}(\mathrm{OH})]^{2+}$ & $\mathrm{Fe}^{3+}+\mathrm{H}_{2} \mathrm{O} \Leftrightarrow[\mathrm{Fe}(\mathrm{OH})]^{2+}+\mathrm{H}^{+}$ \\
\hline$\left[\mathrm{Fe}(\mathrm{OH})_{2}\right]^{+}$ & $\mathrm{Fe}^{3+}+2 \mathrm{H}_{2} \mathrm{O} \Leftrightarrow\left[\mathrm{Fe}(\mathrm{OH})_{2}\right]^{+}+2 \mathrm{H}^{+}$ \\
\hline $\mathrm{Fe}(\mathrm{OH})_{3}$ & $\mathrm{Fe}^{3+}+3 \mathrm{H}_{2} \mathrm{O} \Leftrightarrow \mathrm{Fe}(\mathrm{OH})_{3}+3 \mathrm{H}^{+}$ \\
\hline$\left[\mathrm{Fe}(\mathrm{OH})_{4}\right]^{-}$ & $\mathrm{Fe}^{3+}+4 \mathrm{H}_{2} \mathrm{O} \Leftrightarrow\left[\mathrm{Fe}(\mathrm{OH})_{4}\right]^{-}+4 \mathrm{H}^{+}$ \\
\hline$\left[\mathrm{Fe}_{2}(\mathrm{OH})_{2}\right]^{4+}$ & $2 \mathrm{Fe}^{3+}+2 \mathrm{H}_{2} \mathrm{O} \Leftrightarrow\left[\mathrm{Fe}_{2}(\mathrm{OH})_{2}\right]^{4+}+2 \mathrm{H}^{+}$ \\
\hline $\mathrm{Hen}^{+}$ & $\mathrm{Hen}^{+} \Leftrightarrow \mathrm{en}+\mathrm{H}^{+}$ \\
\hline $\mathrm{H}_{2} \mathrm{en}^{2+}$ & $\mathrm{H}_{2} \mathrm{en}^{+} \Leftrightarrow \mathrm{en}+2 \mathrm{H}^{+}$ \\
\hline Hsalicylate $^{-}$ & Hsalicylate $^{-} \Leftrightarrow$ salicylate $^{2-}+\mathrm{H}^{+}$ \\
\hline $\mathrm{H}_{2}$ salicylate & $\mathrm{H}_{2}$ salicylate $\Leftrightarrow$ salicylate ${ }^{2-}+2 \mathrm{H}^{+}$ \\
\hline HEDTA $^{3-}$ & $\mathrm{HEDTA}^{3-} \Leftrightarrow \mathrm{EDTA}^{4-}+\mathrm{H}^{+}$ \\
\hline $\mathrm{H}_{2} \mathrm{EDTA}^{2-}$ & $\mathrm{H}_{2} \mathrm{EDTA}^{2-} \Leftrightarrow \mathrm{EDTA}^{4-}+2 \mathrm{H}^{+}$ \\
\hline $\mathrm{H}_{3} \mathrm{EDTA}^{-}$ & $\mathrm{H}_{3} \mathrm{EDTA}^{-} \Leftrightarrow \mathrm{EDTA}^{4-}+3 \mathrm{H}^{+}$ \\
\hline $\mathrm{H}_{4}$ EDTA & $\mathrm{H}_{4} \mathrm{EDTA} \Leftrightarrow \mathrm{EDTA}^{4-}+4 \mathrm{H}^{+}$ \\
\hline
\end{tabular}




\section{Figure Captions}

Figure 1 A schematic diagram showing the independent wiring of copper(II) and iron(III) ISEs into a single solid-state ISE array.

Figure 2 A schematic diagram of the wall jet flow cell used in this CFA-ISE study.

Figure 3 A schematic diagram of the CFA manifold used in this study noting that all connections in the CFA manifold were made using Tygon ${ }^{\mathrm{TM}}$ tubing (0.0449 inch I.D., 0.1124 inch O.D.) with the fitting of 3 -stop silicon tubing (2.54 mm I.D.) to the peristaltic pump, and a flow-rate of $5 \mathrm{ml}$ per minute was used.

Figure 4 The MINTEQA2 V3.11 derived speciation data in the calibration buffer as depicted by the $\mathrm{pCu}$ and $\mathrm{pFe}$ versus $\mathrm{pH}$ curves.

Figure 5 CFA response curves for the bielectrode ISE array in the combination buffer to stepwise changes in $\mathrm{pCu}$ and $\mathrm{pFe}$ : (a) $\mathrm{pCu}=15.8$ and $\mathrm{pFe}=20.4$; (b) $\mathrm{pCu}=14.7$ and $\mathrm{pFe}=19.2$; (c) $\mathrm{pCu}=11.9$ and $\mathrm{pFe}=16.4 ;$ (d) $\mathrm{pCu}=8.3$ and $\mathrm{pFe}=13.5 ;$ (e) $\mathrm{pCu}=4.8$ and $\mathrm{pFe}=$ 11.2 .

Figure 6 CFA Nernstian response curves obtained using the bielectrode ISE array: (a) copper(II) ISE; (b) iron(III) ISE. 


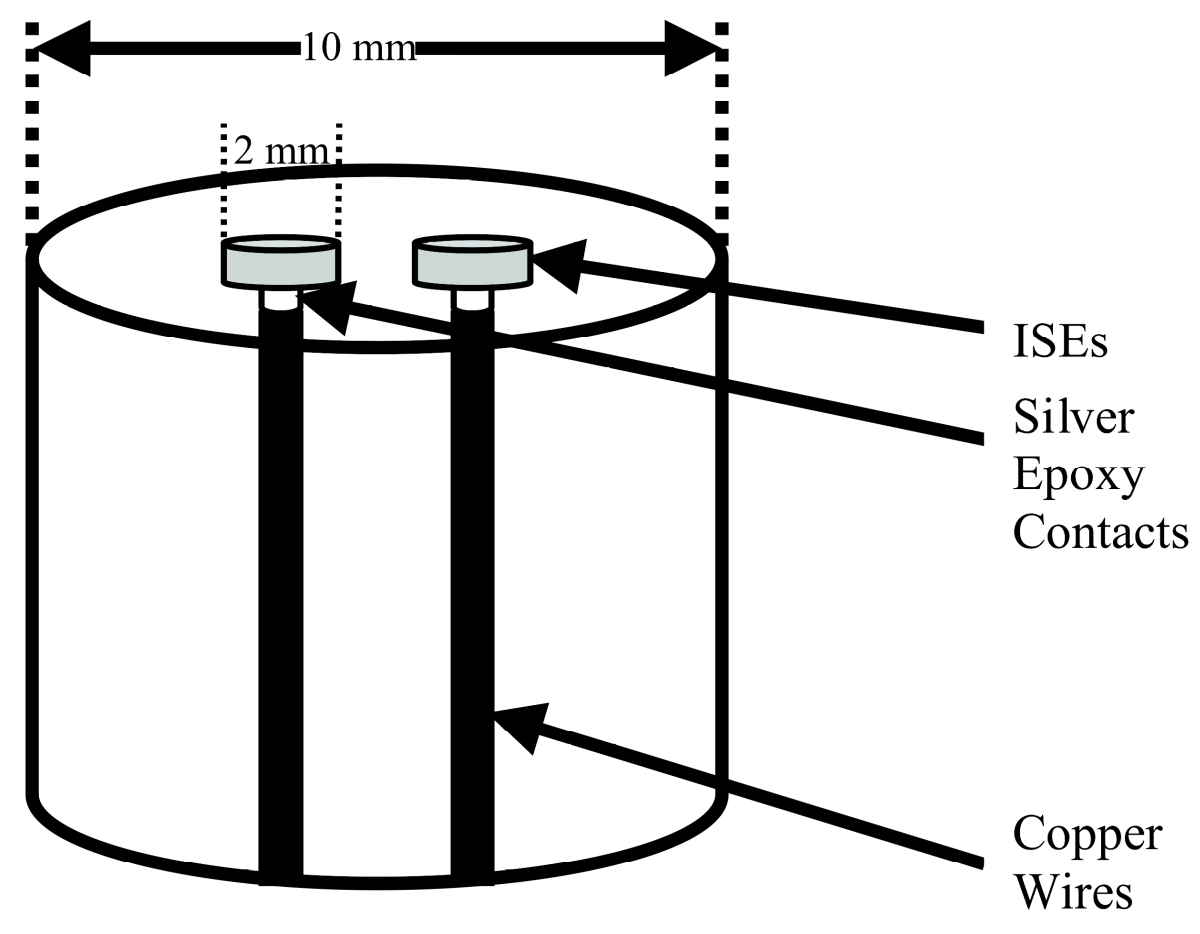

Figure 1 


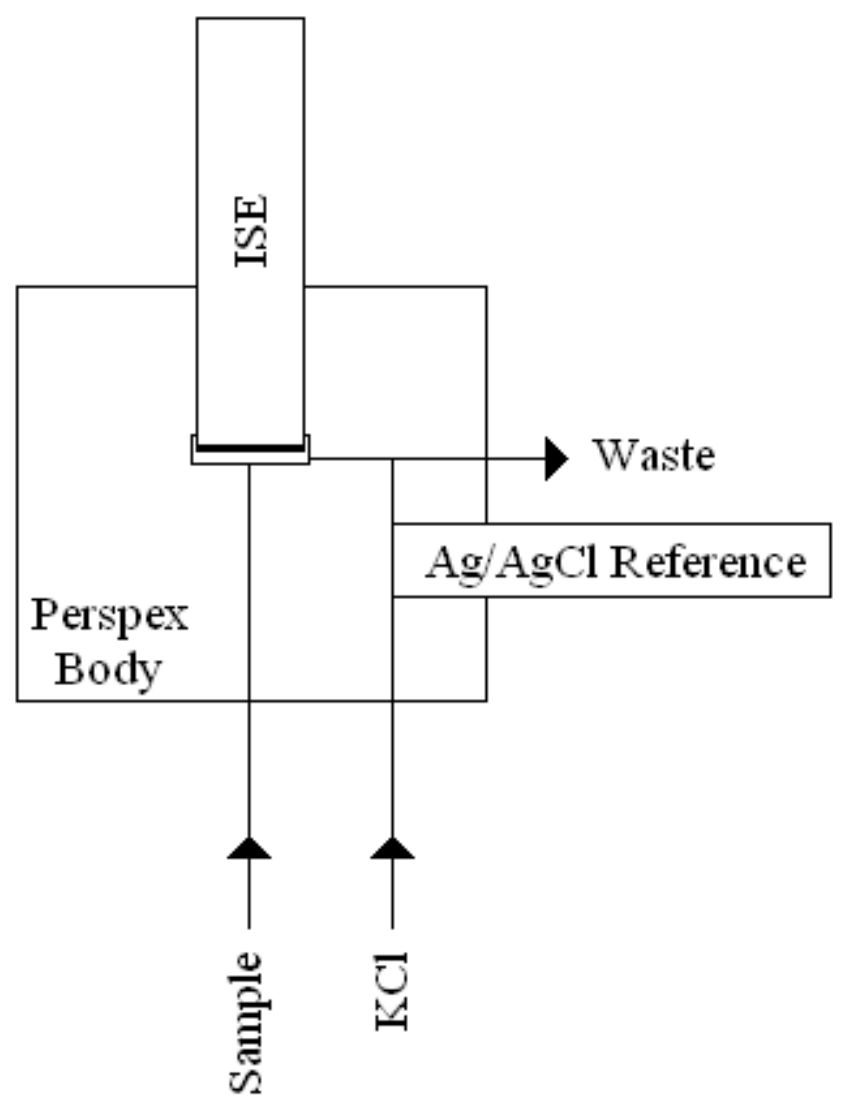

Figure 2 


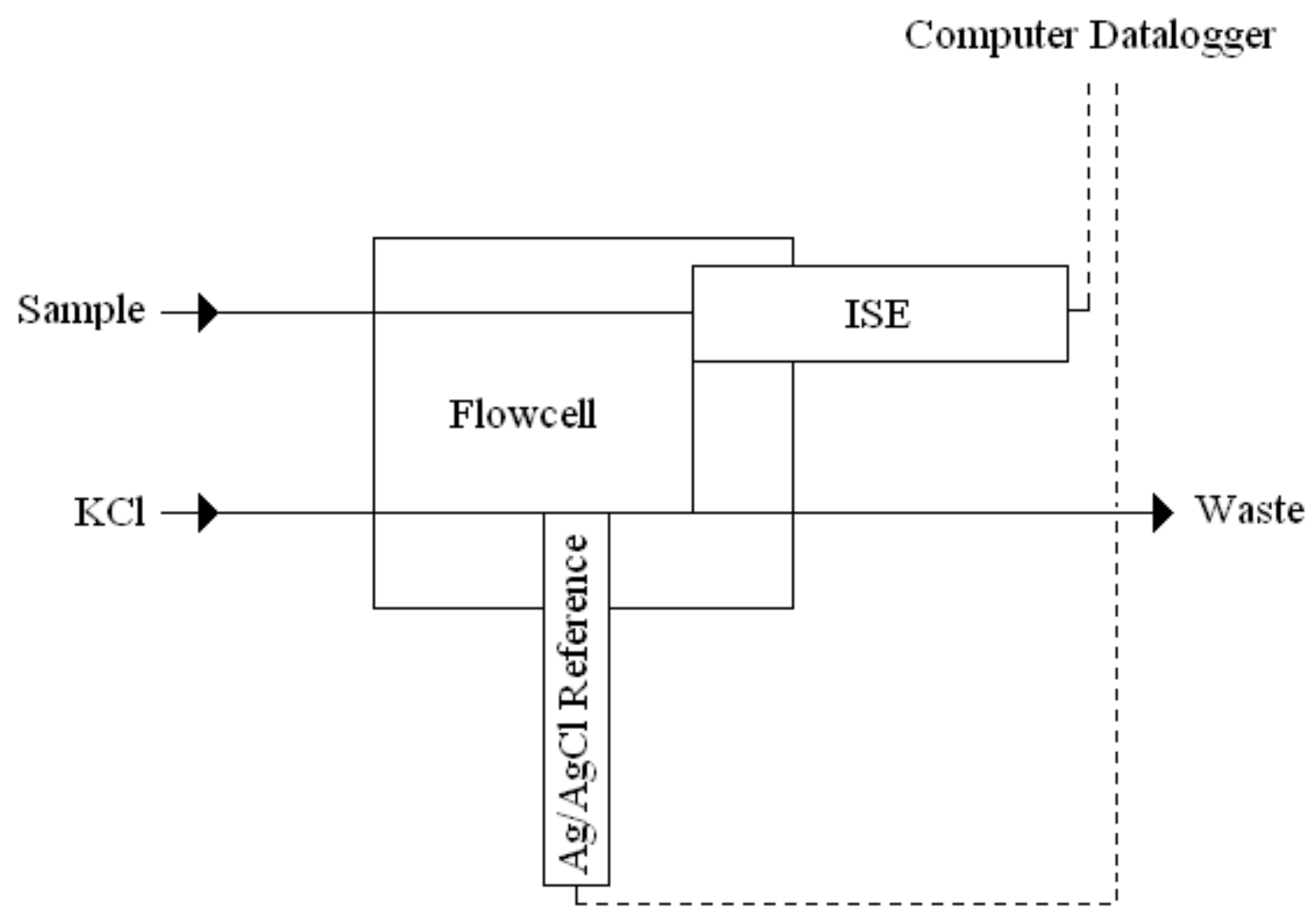

Figure 3 


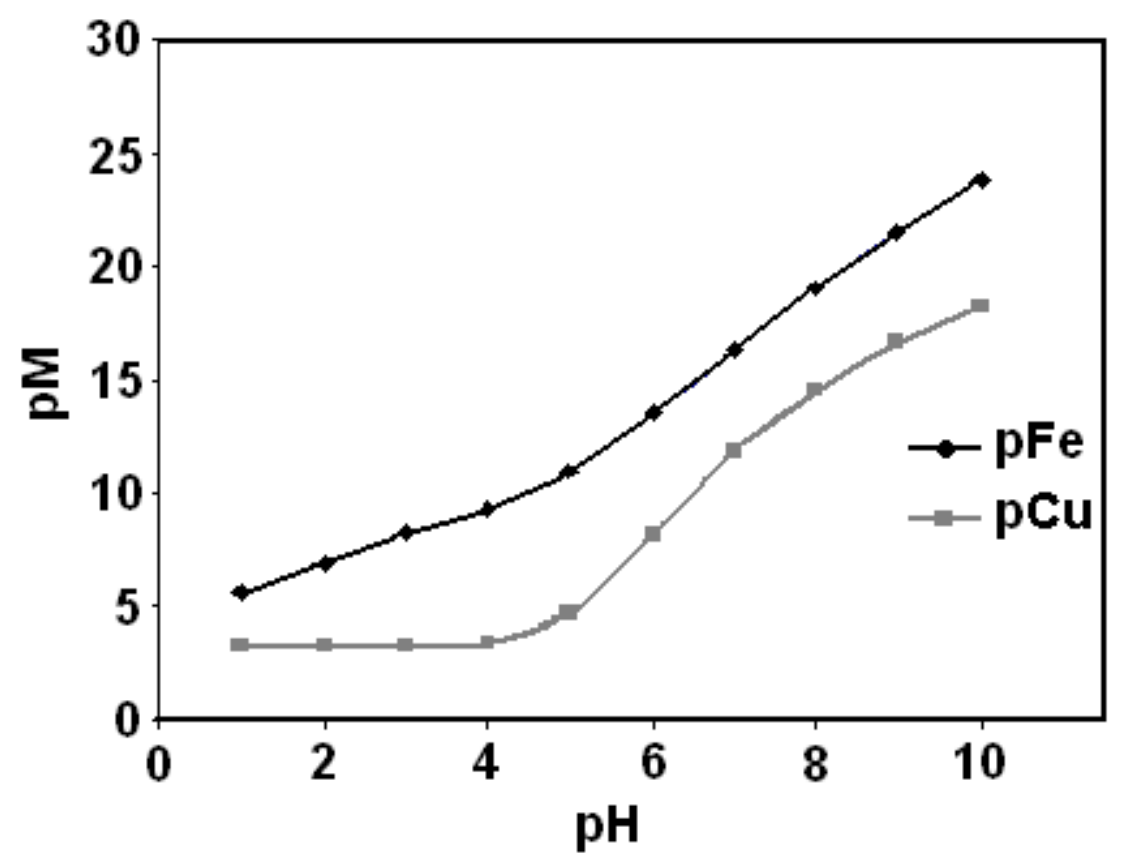

Figure 4 


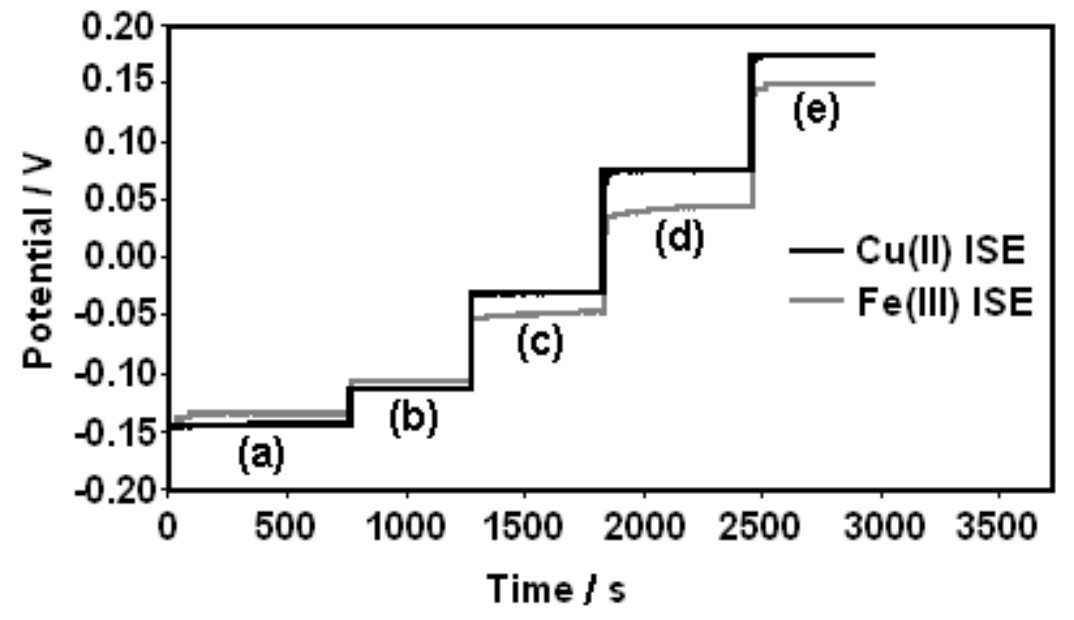

Figure 5 
(a)

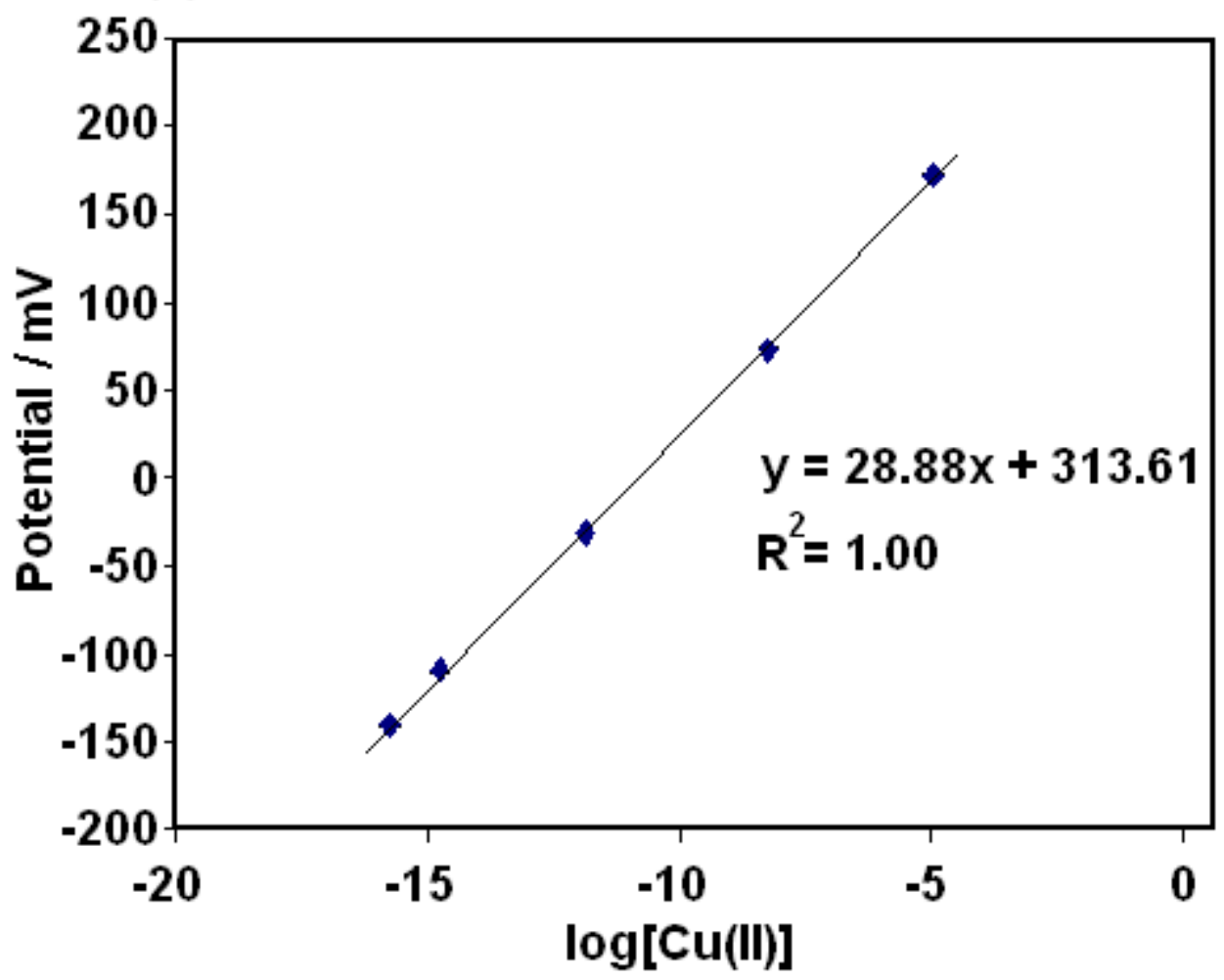

(b)

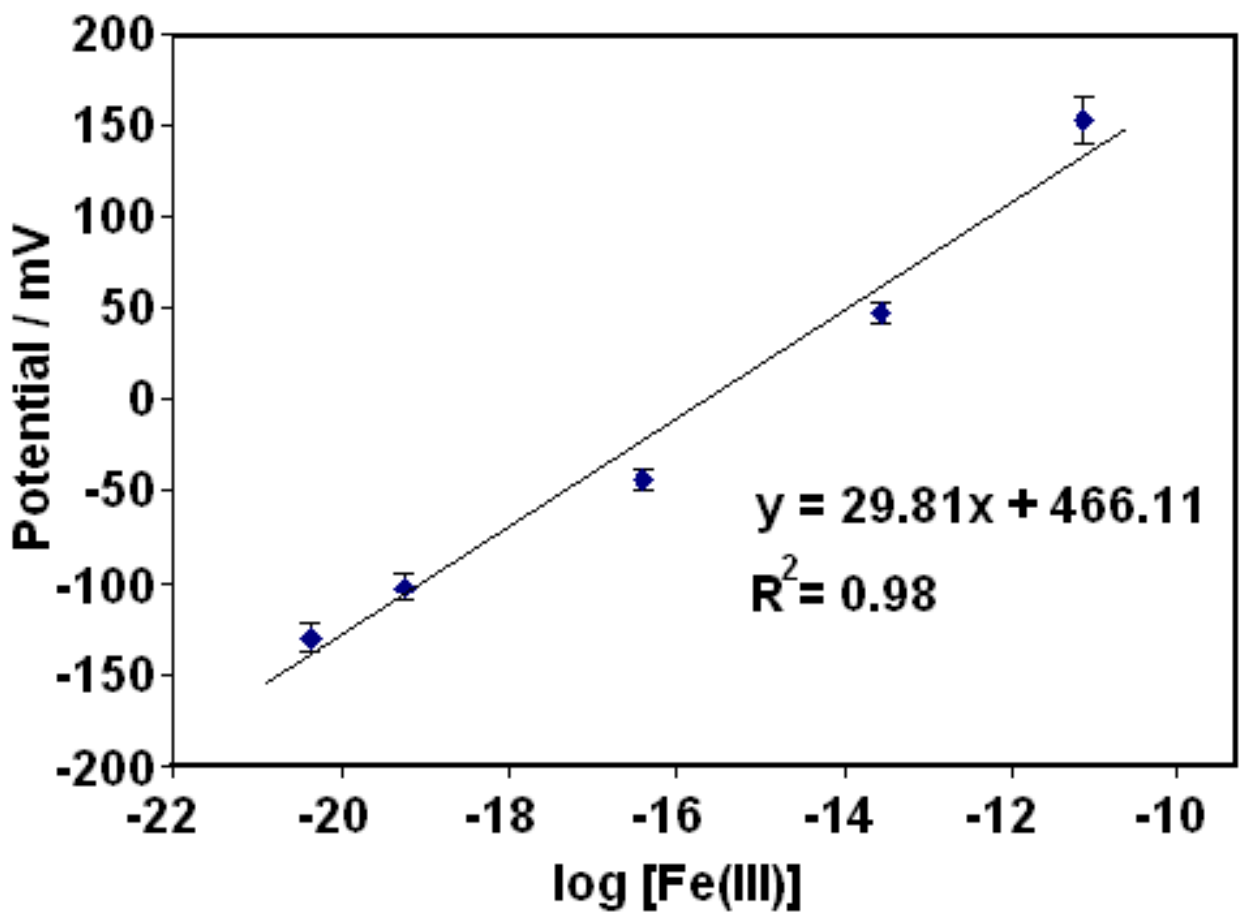

Figure 6 